\title{
Redes de organizações sociais: a inserção da lógica de mercado e a formação de gestores
}

\author{
Rosimeri Carvalhoda Silva* \\ Eloise Livramento Dellagnelo**
}

\begin{abstract}
Resumo
0 campo da cultura, assim como outros campos, tem passado por grandes transformações nos últimos anos. No Brasil, a Lei Rouanet e a criação da figura jurídica das Organizações Sociais são marcos importantes dessa transformação, que implica novos modos de ação e, notadamente, novos modos de captação de recursos e gestão das organizações. No centro dessas transformações, parece estar a inserção da lógica de mercado nas atividades culturais. Fundamentadas nessas percepções, oriundas de estudos realizados no grupo de pesquisa do qual participamos, realizamos um estudo etnográfico em uma rede de organizações não-governamentais denominada Rede Arte e Cidadania, a qual aglutina aproximadamente 30 ONGs que utilizam a arte em suas diversas manifestações para a construção ou recuperação da cidadania de grupos em situação de risco, notadamente crianças de classes desfavorecidas. Os resultados da análise identificam uma forte inserção da lógica de mercado na formação de gestores de ONGs pertencentes à Rede, observada pela discussão concentrada em elaboração de projetos com uma visão predominantemente empresarial, baseada em aspectos quantitativos e, por vezes, em interpretações errôneas.
\end{abstract}

Palavras-chave.: redes, organizações sociais, formação de gestores, mercantilização.

\begin{abstract}
Culture field, as any other field in contemporary society, has gone through huge changes over the last years. In Brazil, the Rouanet Law and the establishment of the juridical institute of Social Organizations are important landmarks of such changes, implying new modes of action and, notably, new ways of fund raising and new parameters of organizational management. At the core of these changes, it appears that the market logic is inserted in cultural activities. Based on these perceptions derived from studies realized by the research group we participate in, we carried out an ethnographic study in a network of non-governmental organizations, named Rede Arte e Cidadania, which encompasses about 30 ONGs that use art in its diverse expressions for the construction or recovery of citizenship in groups under risky situation. The results of this study signal a strong insertion of the market logic in the training process of managers of the ONGs belonging to the network analyzed. Such perception was triggered by the emphasis placed, during the training process of these managers, on the topic of elaborating projects with a predominantly business view.
\end{abstract}

Keywords: networks, social organizations, qualification of managers.

\section{Introdução}

Neste artigo é analisado o processo de formação de uma rede de organizações não-governamentais ligadas ao desenvolvimento ou à recuperação da cidadania através da arte. Todas as organizações envolvidas atuam em Florianópolis, Santa Catarina. O projeto de pesquisa no qual está baseado este estudo tem uma abordagem mais ampla e reflete uma preocupação presente nas atuais investigações do grupo Observatório da Realidade Organizacional. Esse grupo de pesquisa estuda o processo de mercantilização pelo qual parece ter passado as organizações culturais na última década no Brasil, e sua investigação, que vem sendo desenvolvida na rede, dá prioridade à compreensão do processo de construção de identidade das organizações. Entretanto, neste artigo será dado destaque à observação das características das atividades que possam indicar a disseminação do modelo empresarial de gestão ou a busca de um modelo alternativo. Nesse sentido, serão analisados,

\footnotetext{
* Departamento de Ciências da Administração e do Curso de Pós- Graduação em Administração da Universidade Federal de Santa Catarina (CPGA/UFSC). E- mail: rosimeri@ cse.ufsc.br

** Departamento de Ciências da Administração e do Curso de Pós- Graduação em Administração da Universidade Federal de Santa Catarina (CPGA/UFSC). E-mail: eloise@ cse.ufsc.br
} 
especificamente, os encontros voltados para a preparação dos gestores das ONGs, visando à elaboração de projetos.

Estudos já realizados pelo Observatório da Realidade Organizacional têm concluído que muitas das organizações que atuam em áreas que não estavam vinculadas de maneira prioritária ao mercado passam por um processo de mercantilização crescente. Além das transformações observadas, este artigo pretende salientar a adoção de um modelo de gestão empresarial.

A disseminação do modelo empresarial parece estar vinculada a diversos aspectos do campo formado pelas organizações em estudo, seja quanto ao financiamento de suas atividades, ao desenvolvimento turístico de certas regiões, à crescente profissionalização etc. Este estudo objetiva analisar a contribuição que as redes organizacionais formadas por ONGs podem dar para a disseminação ou não do modelo empresarial de gestão. Portanto, a questão central refere-se às atividades (e suas formas) desenvolvidas pela rede específica analisada neste artigo, capazes de contribuir para a disseminação do modelo empresarial de gestão. A preocupação é descobrir se a associação das ONGs em redes pode contribuir para que estas, fortalecidas através dessa interrelação, busquem modelos alternativos de gestão mais adaptados às suas especificidades.

A pesquisa original preocupa-se com a análise da formação da identidade da rede e procura responder a questões como: que valores serão privilegiados pelos atores? Quais estratégias de atuação serão colocadas em prática? De que forma os grupos se articularão para construir a identidade da rede? Quais os conflitos existes e como estes serão solucionados nesse processo de construção de identidade? Como se efetuará a gestão da rede? Que relações de poder podem ser observadas nesse processo de construção de identidade?

Contudo, a participação na rede levou à observação de alguns fatos esclarecedores de outras questões. Foi constatado, por exemplo, que ao buscar manter as suas atividades, as organizações necessitam de financiamento externo. Dessa forma, surgiram novas indagações, as quais norteiam este artigo. Questiona-se como a rede forma os membros das organizações para a elaboração de projetos, quais aspectos são privilegiados nas discussões sobre elaboração de projetos, de que conhecimentos tratam os cursos de formação, qual a relação desses conhecimentos com a atuação da organização e seus objetivos e que atores detêm os conhecimentos (o capital) considerados relevantes pelas organizações envolvidas na rede.

\section{Redes organizacionais}

A noção de redes organizacionais tem sido foco de atenção crescente dos estudos organizacionais, além de estar se disseminando como prática organizacional. De acordo com Carvalho (2002, p.2) o conceito é originário da sociologia e "consiste em atores em nós conectados por laços ou vínculos sociais". A autora utiliza o conceito de Gulatti (1998 apud CARVALHO, 2002, p.2) que define redes como um agrupamento de núcleos (pessoas ou organizações) ligados por um leque de relações sociais (amizades, transferências de fundo etc.) de um tipo especifico.

Outros autores enfatizam aspectos diferentes, como Padolny e Page (1998 apud CARDOSO; ALVAREZ e CAULLIRAUX, 2002,) que definem rede como "uma coleção de atores que estabelecem relações de troca de longo prazo, e que ao mesmo tempo não possuem legitimidade e autoridade para arbitrar e resolver disputas que podem ocorrer durante a troca". Cardoso, Alvarez e Caulliraux (2002, p.9) afirmam que as redes situam-se como formas híbridas de organização entre o mercado (onde a coordenação do trabalho se dá a partir da racionalidade estrita de transações independentes ao longo do tempo) e a hierarquia (onde a coordenação se dá pelo poder formal). Nas redes, surge com grande relevância a coordenação a partir de mecanismos sociais.

Cardoso, Alvarez e Caulliraux (2002) apresentam ainda algumas características das redes:

- são compostas por diferentes atores/organizações que interagem entre si e detém, cada um, um conjunto de recursos;

- as organizações participantes mantêm um razoável grau de independência formal/contratual entre si; 
- existem relações informais de significativa dependência entre seus participantes, que se aprofundam à medida que, dinamicamente, se desenvolvem os laços entre eles;

- as interações entre os nós da rede não se dão em momentos únicos, mas são repetidas ao longo do tempo, configurando padrões e evoluindo;

- a organização em rede pressupõe a existência de objetivos/interesses comuns ou complementares entre os participantes.

Os estudos sobre as redes situam-nas entre duas formas predominantes nas análises organizacionais: a hierarquia e o mercado, como mostra a figura 1. No início, as redes apresentam um caráter bastante informal na sua estruturação, bem como uma considerável fragilidade quanto a tamanho, habilidades desenvolvidas para a gestão das atividades, capacidade de captação de informações e recursos, formação dos membros etc. Neste artigo, embora o objeto de estudo envolva uma rede de organizações sociais, cabe destacar que não será analisada sua estruturação, mas as atividades de formação de gestores que tiveram lugar na Rede Arte. Assim, a abordagem seguirá o conceito de Machado e Machado (1999, p.5) sobre redes de organizações sem fins lucrativos:

por "red" debe entenderse una organización independiente, representativa, participativa, horizontal, interactiva, estable, flexible y corporativa, principalmente integrada por instituciones y personas jurídicas sin ánimo de lucro, que tiene por finalidades:

a) representar, promover, potenciar y defender general, parcial o sectorialmente derechos e intereses comunes de sus afiliadas;

b) tratar de lograr de los órganos, organismos y funcionarios del Estado una creciente participación, directamente $\mathrm{o}$ através de la misma red, en los asuntos propios de la comunidad; así como la adopción o modificación de las políticas y leyes que de una manera u otra puedan interesar o afectar los intereses comunes que representa;

c) propiciar la actuación armónica y coordinada de sus integrantes en los asuntos que les conciernan o interesen;

d) facilitar el intercambio entre ellas de informaciones, conocimientos y experiencias para un mejor y más económico aprovechamiento de sus recursos;

e) asesorarlas y guiarlas en el establecimiento y aplicación de sus respectivos sistemas de autosostenibilidad y autorregulación); y

f) realizar o ejecutar (por sí misma o conjuntamente con otros entes) investigaciones, estudios, obras o programas sociales, en las materias de su incumbencia, y que individualmente las instituciones que la integran no podrían realizar o sólo podrían alcanzar de una manera parcial o reducida o con esfuerzos desproporcionados con relación a sus respectivos recursos. 
Figura 1

Hierarquia, rede e mercado

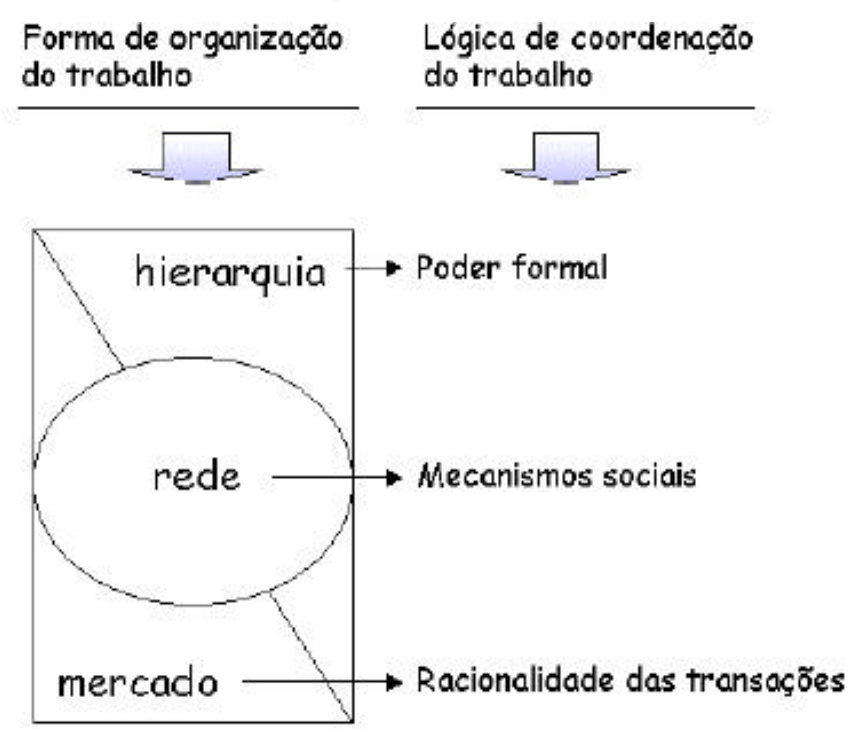

Fonte: Cardoso, Alvarez e Caulliraux (2002, p.10).

Como toda construção social, as ONGs e suas redes estão inseridas num contexto onde acontecem jogos de poder pelos quais são influenciadas e aos quais influenciam. A própria organização em redes pode implicar transformações políticas nas relações entre as organizações envolvidas e os parceiros com os quais estabelecerão ações conjuntas. Portanto, a análise do poder e a análise da transformação dos tipos de capital que circulam e recebem valorização nessas relações são essenciais para a compreensão do processo.

\section{0 poder simbólico}

A compreensão do conceito de poder simbólico tal como desenvolvido pelo sociólogo Pierre Bourdieu implica entender, pelo menos, dois outros conceitos, o de capital e o de habitus. Idéia central na obra de Bourdieu, o conceito de campo também é importante, na medida em que o habitus e a posse de um tipo de capital serão importantes num campo e não em outros. Contudo, a análise apresentada neste artigo não incluirá a noção de campo, pois o estudo não envolve o conjunto de atores em relação ao campo das organizações culturais sem fins lucrativos de Florianópolis, mas uma única rede dessas organizações. No entanto, é importante compreender que para o autor o conceito de campo envolve um conjunto de relações sociais, no qual são verificadas lutas por recursos e por acesso ao campo.

Para Bourdieu, o conceito de capital se apresenta de diferentes formas, não se restringindo exclusivamente ao capital econômico, como na maioria das análises (EVERETT, 2002, p.62). O capital econômico consiste na riqueza material, monetária, mas podemos considerar também o capital cultural, que, segundo Everett (2002), quebra a idéia de que o capital deve necessariamente ser material para ser valioso. O capital cultural inclui o conhecimento, as habilidades, os gostos, o estilo de vida e as qualificações. Pode-se ainda considerar o capital lingüístico - um subconjunto do capital cultural - como a habilidade de manipular estruturas complexas de linguagem e o capital social, definido como os recursos existentes numa rede de relações sociais (EVERETT, 2002). Entretanto, para o autor, a forma mais instigante de capital é o capital simbólico. Essa forma é oriunda de outras formas de capital; ou seja, tem origem na posse de capitais que são legitimados em determinado campo. Assim, pode-se afirmar que o capital simbólico é a forma mais valiosa de capital, porque é somente na forma de capital simbólico que as outras formas de capital, e sobretudo o capital econômico, poderão exercer poder de modo duradouro. Para Everett (2002, p. 63): 
Symbolic capital is found in the form of prestige, renown, reputation, and personal authority (CRONIN, 1996). Symbolic capital gives one 'the power to consecrate' (BOURDIEU, 1989, p.23) and impose both the legitimate vision of the world and the way 'in which social fields are organized in particular hierarchies of positions of capital' (MEISENHELDER, 1997, p.169).

A capacidade dos atores que detêm um determinado tipo de capital em um campo, de transformá-lo em capital simbólico, implica poder simbólico para esses detentores. Para Bourdieu, o que caracteriza poder é o reconhecimento, por parte dos atores sociais, da posse de um recurso, ou capital, e pelo valor que estes dão a esse capital específico. Segundo Bourdieu (2000, p.15) "o poder simbólico, poder subordinado, é uma forma transformada, quer dizer, irreconhecível, transfigurada e legitimada das outras formas de poder"; é quase mágico e permite obter, suavemente, o que poderia ser obtido pela força física ou econômica. No espaço social os atores buscam esse poder simbólico como forma de impor sua própria visão do mundo; o que está, por sua vez, ligado à posição que eles detêm na relação de forças existentes no campo em um dado momento.

De acordo com Everett (2002, p.66), “onde a questão da legitimidade não é colocada, onde as lutas simbólicas não encontram lugar, encontra-se a sociedade doxica, uma sociedade com uma ordem cosmológica e política percebida não como arbitrária, mas como auto-evidente". O autor afirma ainda que, para Bourdieu, quando a doxa ou o senso comum produzem uma distribuição desigual de capital pessoal, temos a violência simbólica. Para Bourdieu, a violência simbólica é uma violência suave e disfarçada, exercida com a cumplicidade daquele que a sofre (BOURDIEU, 2000).

No conceito de poder simbólico, não é só o capital econômico que é capaz de determinar posições de poder, não é só o dinheiro que importa. Como diria o sociólogo, o capital cultural (os diplomas, os títulos, os conhecimentos adquiridos, os códigos culturais, a linguagem e o modo de se comportar), somado ao capital social (rede de relações na sociedade), constitui uma fonte de poder útil para a determinação e a reprodução das posições sociais.

Para Bourdieu (1999), o conceito de habitus refere-se ao conjunto de "ferramentas" simbólicas adquiridas pelos jogadores no campo político. Os habitus são gestos, pensamentos e formas de estar que os indivíduos incorporam de tal forma, que já não têm consciência deles.

O conceito de habitus, que é transversal à obra do autor, torna-se fundamental na construção de seus argumentos. Refere-se à capacidade criativa dos agentes sociais, mas, ao mesmo tempo, é construído no espaço contextual e está sujeito a processos sociais. Para Bourdieu (1999 p.98) "um campo não é produto de uma ação deliberada de criação; ele segue regras, ou regularidades, que não são explicitadas ou codificadas".

Se no campo político as posições de poder são adquiridas pela manipulação simbólica da vida social, logo, o controle dos significados sociais é a principal fonte de poder dos atores dentro do campo. Por um lado, eles são gerados pelo grupo dominante (indivíduos conhecedores das regras do jogo político e detentores do habitus necessário à participação no jogo) dentro de seu campo intelectual. Por outro lado, essa conquista de posições de poder depende do nível em que esse discurso obtém adesão e legitimidade por parte dos "leigos" (indivíduos ou instituições que estão fora do campo de poder, mas que formam o capital social necessário para legitimar os conceitos vigentes na vida social).

A noção de habitus nos remete a dois modelos de ação opostos: o determinismo, que restringe a ação no quadro de limitações impostas, e o indivíduo autônomo, livre e racional. O habitus, uma segunda natureza, é um condicionamento, diferente do hábito que é tão somente uma rotina. A importância dessa noção pode ser percebida, tendo em vista que aqueles que não dispõem do habitus são considerados outsiders.

Cada campo tem associadas certas práticas, valores, estilos, gostos e restrições; em suma, um certo habitus, produzido pelas condições sociais relacionadas às posições correspondentes e pela intermediação desse habitus e de suas capacidades estruturantes (BOURDIEU, 1996, p.21). Segundo Misoczky (2001, p.49) "o habitus é um sistema de disposições duráveis, estruturas estruturadas que operam como estruturas estruturantes; isto é, como princípios geradores e organizadores das práticas e representações". 
A análise das transformações que podem estar envolvidas na participação das ONGs na rede e, mais amplamente, das transformações do campo das organizações não-governamentais que desenvolvem ações de cultura e cidadania implica a consideração dos jogos de poder, das transformações do capital utilizado nas trocas e do processo de construção de um novo habitus.

\section{Método}

Este estudo caracteriza-se como um estudo etnográfico no qual o pesquisador adota uma postura de observador, tomando parte nas diversas atividades desenvolvidas pela rede em estudo. A pesquisa etnográfica está associada aos estudos antropológicos e refere-se, segundo Babbie (1998), a uma observação naturalista e a uma compreensão holística de culturas e subculturas. Segundo Atkinson e Hammersley (1994, p.248), estudos etnográficos têm as seguintes características:

- grande ênfase na exploração da natureza particular de um fenômeno social específico;

- tendência para trabalhar, primordialmente, com dados não estruturados, a investigação de um pequeno número de casos, e

- efetua uma análise de dados que envolve explicitamente a interpretação de significados e funções da ação humana.

O acesso da pesquisadora à Rede Arte ocorreu de maneira bastante natural, sem uma relação formal anterior. A primeira reunião da rede foi convocada através de mensagem publicitária em uma rede de televisão local, evidenciando grande abertura à participação. Dessa forma, a pesquisadora dirigiu-se à reunião como todos os demais membros, gestores ou participantes de organizações não-governamentais que utilizam a arte para o desenvolvimento da cidadania, primordialmente, em crianças e adolescentes. Assim, num primeiro momento, mais especificamente no primeiro e segundo encontros, assistiu-se às reuniões sem qualquer identificação, pois isso não era exigido de nenhum dos participantes. Durante as reuniões, foram anotados os aspectos que pareceram mais relevantes às discussões.

No terceiro encontro, foi então solicitado aos participantes que se identificassem, e nesse momento expusemos nossa proposta de investigação, a qual foi recebida sem restrições. Participamos de todos os encontros temáticos da rede, durante os anos de 2003 e 2004, que aconteceram de março a dezembro, mensalmente, com duração de quatro horas cada encontro. Participamos também do curso de formação de gestores para a elaboração de projetos, realizado durante cinco encontros de quatro horas.

Adiante, será descrito no que consiste a Rede Arte e, então, serão analisados dois eventos considerados mais importantes para os objetivos deste artigo: uma workshop sobre projetos sociais e um curso de formação para a elaboração de projetos.

\section{A Rede Arte}

A Rede Arte foi fundada em 2002, por iniciativa de uma Fundação ligada a um grande grupo de mídia (FM), uma entidade de direito privado, mas de fins públicos. A entidade se autoclassifica como uma agência de fomento ao desenvolvimento social sustentável. A idéia de criação da rede nasceu, segundo seus coordenadores, da possibilidade de auxiliar tecnicamente organizações que haviam ingressado com projetos junto à fundação, mas que não tinham sido contempladas com apoio financeiro ou técnico. Além disso, a experiência dos integrantes da fundação apontava para a necessidade de capacitar os membros das organizações, principalmente, quanto à elaboração de projetos. Dessa forma, através de convite às organizações que haviam participado do processo de seleção de projetos, os coordenadores iniciaram encontros entre essas organizações, coordenados pelos integrantes da FM. 
Nosso ingresso na rede aconteceu um ano após sua fundação, na primeira reunião realizada em 2003, quando duas outras instituições passaram a apoiar a rede, A Fundação Estadual de Cultura (aqui identificada como FEC) e uma organização vinculada a uma associação comercial (aqui identificada como OSC). A FEC é uma pessoa jurídica de direito público, instituída em 1979, e está ligada à Secretaria de Estado da Organização do Lazer de Santa Catarina. O OSC é uma instituição de abrangência nacional, criada em 13 de setembro de1946, na cidade do Rio de Janeiro. Seu principal objetivo é desenvolver trabalhos socioeducativos para os comerciários, em cinco áreas de atuação: saúde, educação, cultura, lazer e assistência.

A partir dessa primeira reunião, os encontros passaram a ser realizados mensalmente na sala de cinema do Centro Integrado de Cultura, órgão ligado à FEC. No folder distribuído pelos coordenadores, a Rede Arte é definida como "uma rede social formada por profissionais, organizações e artistas comprometidos em fazer da arte um caminho para o desenvolvimento humano, inclusão social de crianças e adolescentes".

Segundo o primeiro documento da rede, de 2002, distribuído por e-mail, seu objetivo é:

Propiciar que a arte tenha um papel fundamental no desenvolvimento da expressividade humana, dando nova forma ao espaço social, onde os direitos e deveres sejam socialmente construídos com a consciência de que este pode ser um caminho promissor na reflexão e possível luta frente aos valores instituídos, no sentido de buscar reciprocidade de valor e a aceitação de alteridade. Assim, acreditamos estar construindo uma cidadania ativa.

Um folder de 2003 aponta como objetivos formais:

- articular projetos sociais e ações educativas que utilizam a arte e a cultura como canais de desenvolvimento humano e cidadania;

- capacitar profissionais e voluntários que atuam nos projetos sociais para qualificar as ações desenvolvidas;

- mobilizar a sociedade para a importância da arte como atividade educativa e de desenvolvimento humano.

Além das reuniões mensais, a Rede Arte mantém um grupo de discussão na internet, com 116 inscritos ativos, atualmente. Esse número não representa a quantidade de organizações vinculadas à rede, pois vários membros de uma mesma organização podem participar do grupo, bem como profissionais de arte isolados, não vinculados a uma organização. No grupo de discussão são divulgadas informações consideradas interessantes para os membros, como apresentações de arte, editais de chamada de projetos, cursos, notícias relacionadas à arte e cidadania, anúncio de procura de profissionais para integrarem alguma das organizações participantes etc. Uma primeira análise assistemática das mensagens trocadas pelo grupo (uma análise sistemática está sendo realizada) indica a inexistência de discussões sobre conteúdos que poderiam ser significativos, relacionados à arte e/ou à cidadania. Em 2003, a partir de comentário de uma coordenadora sobre uma mostra de grupos de Boi-de-mamão - manifestação folclórica da Ilha de Santa Catarina -, teve início um debate, quando alguns participantes criticaram a característica competitiva da mostra e, na visão desses participantes, os critérios equivocados dessa competição. A grande maioria das mensagens trocadas (607 mensagens até 15.7.2004) não apresenta os mesmos conteúdos e se restringe à divulgação de informações. A evidência maior dessa ausência de discussões está na comemoração da moderadora do grupo diante das discussões entre alguns participantes sobre a referida mostra.

Desde o primeiro encontro do qual participamos, uma questão parecia central para a análise da rede: a construção de sua identidade; ou seja, a definição do que esse grupo queria ser, do que queria fazer e do que almejam seus participantes. O comentário de uma palestrante visitante, logo na primeira reunião, pôde mostrar o quanto essa questão é importante, ou deveria ser, do ponto de vista do analista. Depois de breve exposição sobre uma rede semelhante em outro estado do Brasil - rede essa já bastante consolidada -, a palestrante assistiu à continuidade da reunião. $\mathrm{O}$ tema principal parecia ser a preocupação com a captação de recursos. $\mathrm{O}$ coordenador solicitava aos presentes sugestões para as atividades a serem realizadas. A grande maioria concentrava-se em aspectos como convidar órgãos financiadores para falarem de seus critérios, proporcionar cursos de elaboração de projetos, divulgar fontes de financiamento e trocar experiências com organizações 
financiadas. Uma sugestão sobre a importância de se discutir a ideologia, a visão sobre o que se quer como um mundo melhor, é descartada por uma coordenadora sob a alegação de que "a ideologia pode unir e desunir". Ao ser questionada pela visitante sobre qual o sentido da rede, e sobre o fato de a sustentação financeira ser importante, mas a identidade ser crucial, a coordenadora respondeu que estar articulado era um dos critérios de seleção dos projetos. Não ficou claro se a coordenadora colocava a rede como um importante meio para que os projetos obtivessem financiamento - sendo esse o sentido da rede -, ou se descartava a discussão sobre identidade, por julgar que o fato dos projetos incluírem uma certa articulação já resolvia o problema. Nossa interpretação aponta para o primeiro sentido.

$\mathrm{Na}$ workshop sobre elaboração de projetos, o grupo é convidado a elaborar uma proposta para supostos avaliadores; no caso, membros da rede, representantes das organizações apoiadoras. O grupo resolve fazer uma apresentação sobre o Boi-de-mamão, que é trabalhado com frequiência pelas organizações não-governamentais que estimulam a cidadania através da arte. Diante do posicionamento de um dos integrantes sobre a importância de definir o objetivo da atividade, outros reagem afirmando que este já está colocado, ou seja, o objetivo é desenvolver a proposta. Há uma discussão sobre o objetivo e a necessidade de esclarecê-lo e formalizá-lo, o que é realizado por um integrante da FM, que sintetiza o que os integrantes manifestam como objetivo: resgatar a cultura local através da realização de oficinas de Boi-de-mamão com material reciclável.

Após discussão, o objetivo formalizado é o de resgatar a cultura local de crianças de 6 a 14 anos, na região da Agronômica (bairro de Florianópolis). O desenvolvimento das atividades é estruturado do seguinte modo:

- oficinas de criação de personagens;

- oficinas de percussão; e

- oficinas de encenação das histórias do Boi-de-mamão.

Portanto, o que se pode perceber é que a discussão sobre o objetivo é formalista; ou seja, o objetivo de construir o objetivo é exterior ao grupo. A partir desse ponto, o grupo elabora os personagens com o material - papel, lápis, canetas coloridas e material reciclável - proporcionado pelos organizadores, e ensaia uma apresentação cantada com os membros que movimentariam os personagens. Ao final da elaboração, os avaliadores assistem à encenação do Boi-de-mamão, para em seguida fazerem perguntas sobre ao projeto, indagando sobre o número de crianças envolvidas, metas, técnicas utilizadas, habilidades e necessidades orçamentárias. A apresentação do objetivo aos avaliadores é tão formalista quanto foi a sua construção. Ao afirmar "Eu não sou teórico, eu sou prático", um integrante revela sua dificuldade em explicar o objetivo da oficina.

$\mathrm{Na}$ discussão que se segue à apresentação, os avaliadores procuram evidenciar a importância de se estar preparado para perguntas que interessam aos representantes dos potenciais financiadores. Há um certo malestar no grupo, pois a situação o coloca na posição de ter sido focalizado exclusivamente na atividade-fim, sem atentar-se para o que interessaria aos financiadores. Finalmente, um dos avaliadores destaca três pontos principais:

a) a importância que a colocação do ponto e contraponto tem na dimensão da arte-educação (referindo-se a discussões sobre tradicionalismo e nativismo);

b) a importância de se focar nas oficinas, habilidades básicas que possam ser desenvolvidas; e

c) a importância de se utilizar conteúdos, já desenvolvidos em cursos da rede, que digam respeito a objetivos, metodologia, resultados e avaliação.

O avaliador destaca:

Os projetos que mais estão vencendo concursos e recebendo prêmios são os que estimulam o protagonismo dos jovens. Vocês são ícones importantes na vida dessas crianças porque ajudam a resgatar a identidade individual e social delas. Eu não cito mais público-alvo, mas cidadão beneficiário. Ele também é protagonista, não é alvo. 
Embora essa declaração tenha relação evidente com o trabalho desenvolvido pelas ONGs, no que se refere à cidadania, é curiosa a ligação estabelecida pelo participante entre a idéia de protagonista e os concursos e prêmios atribuídos aos projetos sociais; ou seja, a fundamentação da idéia de protagonismo. Em vários dos eventos da rede parece haver uma tensão entre as discussões que o trabalho desenvolvido pelas organizações pode proporcionar e a necessidade percebida de dominar os aspectos que possibilitariam financiamentos, projeção e reconhecimento dessas ONGs. Essa nos parece uma tensão entre as questões internas e externas às organizações que participam da rede.

Com relação ao curso de capacitação em planejamento e roteiro de elaboração de projetos sociais, sua estruturação observou o seguinte cronograma:

- módulo I - O cenário atual da ação social;

- módulo II - Planejamento estratégico/planejamento de projetos orientado por objetivos;

- módulo III - Roteiro de elaboração de projetos sociais;

- módulo IV - Avaliação de projetos sociais; e

- apresentação dos projetos elaborados pelos participantes.

Dois dos responsáveis por módulos são consultores e formadores de gestores de empresas privadas. Os demais são integrantes da FM e de uma das organizações fundadoras da Rede. Pode-se perceber a predominância de conteúdos oriundos da administração e, notadamente, de conteúdos fortemente vinculados à gestão de organizações privadas. Percebe-se também uma forte concentração no conhecimento das exigências dos organismos financiadores e uma clara disposição de adequação das organizações e dos projetos a essas exigências. Isso é verificado a ponto, por exemplo, de não haver nenhuma contestação a respeito dos prazos insignificantes que são vinculados aos objetivos. Pode-se questionar de que forma projetos sociais que lidam com questões de difícil resolução, de difícil percepção de resultados, mesmo a médio prazo, podem trabalhar com prazos considerados longos, de até 12 meses. A incorporação da linguagem da gestão também pode ser percebida nos textos distribuídos e pela dificuldade dos participantes em entender tanto os termos empregados quanto a maneira de construir respostas que sejam coerentes com o significado dos termos.

Percebe-se uma significativa ausência de questionamentos que se contraponham aos critérios estabelecidos. A evidência de que não há formas de se contrapor aos financiadores, pois estes ditam as regras, não pode explicar tal ausência, uma vez que o curso ocorre sem a presença destes, portanto, sem restrições à discussão, que algumas vezes é levantada pelo próprio instrutor. Desse modo, parece que há, de antemão, uma subordinação aos critérios dos financiadores e o interesse de conhecê-los e dominá-los. Percebe-se a transformação do capital econômico dos financiadores em capital simbólico, em poder simbólico, uma vez que perseguindo o primeiro, os gestores incorporam a ideologia que o acompanha. É importante lembrar que "o poder simbólico, poder subordinado, é uma forma transformada, quer dizer, irreconhecível, transfigurada e legitimada das outras formas de poder". Assim, os eventos da rede parecem evidenciar uma busca de compreensão e incorporação dos conceitos e práticas dos detentores do capital econômico, legitimando-os. 


\section{Quadro 1}

Planilha marco lógico, adaptada de apostila de curso de elaboração de projetos

\begin{tabular}{|c|c|c|c|}
\hline Descrição sumária & $\begin{array}{l}\text { Indicadores } \\
\text { objetivamente } \\
\text { comprováveis }\end{array}$ & $\begin{array}{l}\text { Fontes de comprovação } \\
\text { (verificação) }\end{array}$ & Pressupostos \\
\hline $\begin{array}{l}\text { Objetivo superior (OS) } \\
\text { ou de desenvolvimento } \\
\text { do projeto (OD) para o } \\
\text { qual o projeto deverá } \\
\text { contribuir }\end{array}$ & $\begin{array}{l}\text { Como vamos medir o } \\
\text { conteúdo do Objetivo } \\
\text { superior? } \\
\text { qualidade, quantidade, } \\
\text { duração, local e grupo } \\
\text { destinatário } \\
\text { Indicadores de impacto }\end{array}$ & $\begin{array}{l}\text { Que documentos, } \\
\text { elaborados no projeto, ou } \\
\text { provenientes de outras } \\
\text { fontes, podem ser } \\
\text { utilizados para } \\
\text { comprovar os indicadores } \\
\text { a serem medidos? }\end{array}$ & $\begin{array}{l}\text { Quais os fatores externos } \\
\text { necessários para que o } \\
\text { Objetivo superior (OS) } \\
\text { seja mantido no longo } \\
\text { prazo? }\end{array}$ \\
\hline $\begin{array}{l}\text { Objetivo do projeto (OP) } \\
\text { com que contribuímos } \\
\text { para alcançar o Objetivo } \\
\text { superior (OS) }\end{array}$ & $\begin{array}{l}\text { Como medir o conteúdo } \\
\text { do Objetivo do projeto } \\
\text { (OP)? } \\
\text { idem } \\
\text { Indicadores de } \\
\text { efetividade }\end{array}$ & Idem & $\begin{array}{l}\text { Quais os pressupostos } \\
\text { para que o Objetivo } \\
\text { superior (OS) seja } \\
\text { alcançado? }\end{array}$ \\
\hline $\begin{array}{l}\text { Resultados a serem } \\
\text { obtidos (quantidade e } \\
\text { qualidade) para se } \\
\text { alcançar o efeito } \\
\text { esperado (OP): } \\
\text { curto prazo ( } 2 \text { meses) } \\
\text { médio prazo ( } 6 \text { meses) } \\
\text { longo prazo (12 meses) }\end{array}$ & $\begin{array}{l}\text { Como medir o conteúdo } \\
\text { dos resultados? } \\
\text { Idem } \\
\text { Indicadores de } \\
\text { desempenho }\end{array}$ & Idem & $\begin{array}{l}\text { Que pressupostos (quanto } \\
\text { aos resultados) são } \\
\text { necessários para que o } \\
\text { Objetivo do projeto (OP) } \\
\text { seja alcançado? }\end{array}$ \\
\hline $\begin{array}{l}\text { Atividades - pacote de } \\
\text { medidas do } \\
\text { projeto, para alcançar } \\
\text { resultados pretendidos: } \\
\text { Atividade } 1.1 \\
\text { ação } 1.1 .1 \\
\text { Atividade } 2.1\end{array}$ & $\begin{array}{l}\text { Quanto custa ou quais os } \\
\text { insumos requeridos } \\
\text { (incluindo } \\
\text { pessoal) para executar } \\
\text { cada atividade? } \\
\text { Indicadores operacionais }\end{array}$ & $\begin{array}{l}\text { Que documentos } \\
\text { comprovam os } \\
\text { indicadores a serem } \\
\text { medidos? }\end{array}$ & $\begin{array}{l}\text { Que pressupostos } \\
\text { (definidos como fatores } \\
\text { externos quanto às } \\
\text { atividades) são } \\
\text { necessários para se } \\
\text { conseguir os resultados? }\end{array}$ \\
\hline & & & $\begin{array}{l}\text { Condições prévias e } \\
\text { requisitos para } \\
\text { implementar as } \\
\text { atividades }\end{array}$ \\
\hline
\end{tabular}

\section{Conclusões}

A rápida análise aqui exposta não pode apresentar toda a riqueza da observação realizada. No entanto, é possível evidenciar o poder dos atores que dominam conhecimentos ligados à gestão; atores esses oriundos de organizações com amplo conhecimento da gestão de organizações privadas. Esse domínio do capital cultural garante aos seus detentores uma posição que possibilita transformar esse capital em capital simbólico, não questionado pelos demais atores, os quais, na busca pela sobrevivência, auxiliam os detentores desse capital simbólico a estabelecer uma visão de mundo que oculta tal controle e seu significado.

Assim, é possível concluir que pela maneira como estão sendo formados gestores em redes de organizações sociais e como eles são capacitados através dos encontros da Rede Arte e Cidadania, fica evidente a busca desses gestores por conhecimentos específicos de administração. Os gestores das organizações não- 
governamentais buscam um conhecimento que possibilite às suas organizações realizarem suas atividades-fim. Procuram um conhecimento que, ao mesmo tempo, vem auxiliando a construir no campo uma visão de mundo homogênea sobre como realizar tais atividades, a fim de obter recursos. Isso significa que ao invés dos processos de apoio se adequarem às finalidades da organização, parece haver um movimento inverso, que prioriza a gestão e põe em risco a atenção dada àquilo que a organização pretende com a sua atuação.

Essa percepção nos leva a sugerir que o desenvolvimento de conhecimento específico sobre esse tipo de organizações, suas necessidades e características próprias - bem como a formação, não dos gestores de ONGs, mas dos gestores responsáveis pela concessão de financiamentos - é essencial para que essas organizações não percam suas características. É igualmente fundamental para que não sofram com o processo de burocratização inerente à difusão do conhecimento em gestão, o qual tende à transformação dos meios em fins.

\section{Referências bibliográficas}

ATKINSON, P.; HAMMERSLEY, M. Ethnography and participant observation. In: DENZIN, N.; LINCOLN, Y. Handbook of qualitative research. London: Sage, 1994.

BABBIE, E. The practice of social research. Belmont, CA: Wadsworth Publishing Company, 1998.

BOURDIEU, P. 0 desencantamento do mundo. São Paulo: Perspectiva, 1979.

Sociologia. São Paulo: Ática, 1983.

Razões Práticas: sobre a teoria da ação. Campinas: Papirus, 1996.

A economia das trocas simbólicas. 5.ed. São Paulo: Perspectiva, 1999.

0 poder simbólico. 3.ed. Rio de Janeiro: Bertrand Brasil, 2000.

. Razões práticas: sobre a teoria da ação. 2.ed. Oeiras: Celta editora, 2001.

; HAACKE, H. Livre- troca. Rio de Janeiro: Bertrand Brasil, 1995.

; WACQUANT, L. J. D. An invitation to reflexive sociology. Chicago: Chicago University Press, 1992.

CARDOSO, V. C.; ALVAREZ, R. R; CAULLIRAUX, H. M. Gestão de competências em redes de organizações: discussões teóricas e metodológicas acerca da problemática envolvida em projetos de implantação. Encontro da Associação Nacional de Programas de Pós-Graduação em Administração - Enanpad, Anais... Salvador: ANPAD, 2002, 1 CD-ROM.

CARVALHO, M. R. O. Redes sociais: convergências e paradoxos na ação estratégica. In: Encontro da Associação Nacional de Programas de Pós-Graduação em Administração - ENANPAD, Anais..., Salvador: ANPAD, 2002, 1 CD-ROM.

EVERETT, J. Organizational research and the praxeology of Pierre Bourdieu. Organizacional Research Methods, v.5, n.1, p.56- 80, Jan. 2002.

GULAT, Ranjay. Alliances and Networks, Strategic Management Journal , vol.19,1998, p. 293-317.

MACHADO, A. L. ; MACHADO, M. A. I. Las redes como instrumentos de transformación social. Caracas: 1999, working paper..

MISOCZKY, M.C. Campo de poder e ação em Bourdieu: implicações de seu uso em estudos organizacionais. Encontro da Associação Nacional de Programas de Pós-Graduação em Administração, 25, 2001, Campinas. Anais... Rio de Janeiro: ANPAD, 2001. 1 CD-ROM.

PADOLNY, J.M . \& PAGE, K.L. Network Forms of Organization. Annual Review Sociology, 24, pp. 57- 76, 1998. 